\title{
The role of multiple arterial grafts during CABG: at the heart of ART
}

\author{
David Paul Taggart ${ }^{1}$ (D)
}

Received: 27 November 2018 / Revised: 7 March 2019 / Accepted: 25 March 2019 / Published online: 27 May 2019

(C) Indian Association of Cardiovascular-Thoracic Surgeons 2019

It is now 51 years since the first systematic description of Coronary Artery Bypass Graft (CABG) surgery by Favaloro in 1968 when he pioneered the use of saphenous vein grafts for surgical coronary revascularisation [1]. Since then, there have been numerous developments to improve both the short- and long-term outcomes of CABG and several of these are recognised and acknowledged in the current issue of the Journal.

Over the last two decades, the two areas that have been most consistently debated in CABG are the roles and potential benefits of multiple arterial grafts and the use of on- or off-pump CABG. The former has been hampered, at least in part, by the absence of evidence from randomised trials [2], while the latter remains controversial because of conflicting evidence from randomised trials [3, 4]. Important lessons have been learned in both areas and have highlighted, in particular, the crucial importance of surgeon experience.

On 26 August 2018, at the European Society of Cardiology annual meeting in Munich, the longawaited 10-year results of Arterial Revascularisation Therapies (ART) trial were presented by Professor Taggart on behalf of the ART investigators at the Hotline Late Breaking Clinical Trial session. The first presentation of the results to a surgical audience was at the European Association of Cardio-Thoracic Surgeons (EACTS) annual meet in Milan in October. The 10-year results have now been published in the New England Journal of Medicine [5].

David Paul Taggart

david.taggart@ouh.nhs.uk

1 Department of Cardiac Surgery, John Radcliffe Hospital, University of Oxford, Oxford OX3 9DU, UK
ART was essentially designed to determine if two arterial grafts offered a long-term survival advantage over a single arterial graft during CABG. At the time of its conception in 2002, it was believed that the only artery that offered a survival advantage over the exclusive use of saphenous vein grafts was the internal thoracic artery (ITA). Consequently, between June 2004 and December 2007, 3102 patients were randomised to single (SITA) or bilateral (BITA) ITA grafts in 28 centres in seven countries. The 10 -year results of ART were presented both on an intention to treat (ITT: randomised) analysis and an as-treated (AT: nonrandomised) analysis. The as-treated analysis was performed because $40 \%$ of patients in the ART trial actually had a different treatment from that initially proposed.

In the ITT analysis, there was no difference in mortality between BITA and SITA at 10 years nor in the composite endpoints of mortality, myocardial infarction (MI), or stroke (Fig. 1). In contrast, in the AT analysis, there was a significant survival benefit and a significant reduction in the composite endpoint in favour of more than one arterial graft (Fig. 2).

Because it preserves the principle of randomisation, the ITT analysis is more scientifically robust than the AT analysis. However, the ITT analysis is confounded by the fact that $40 \%$ of the ART patients actually received a different treatment from that initially proposed: in the BITA group 14\% actually received a SITA graft, while $4 \%$ of SITA patients actually received BITA grafts and additionally, $22 \%$ of the SITA patients received a radial artery. And although baseline clinical characteristics were similar between the AT and ITT patient cohorts, it must be emphasised again that the former analysis is not randomised and potentially susceptible to unknown confounding factors. 
a Death from Any Cause at $10 \mathrm{Yr}$

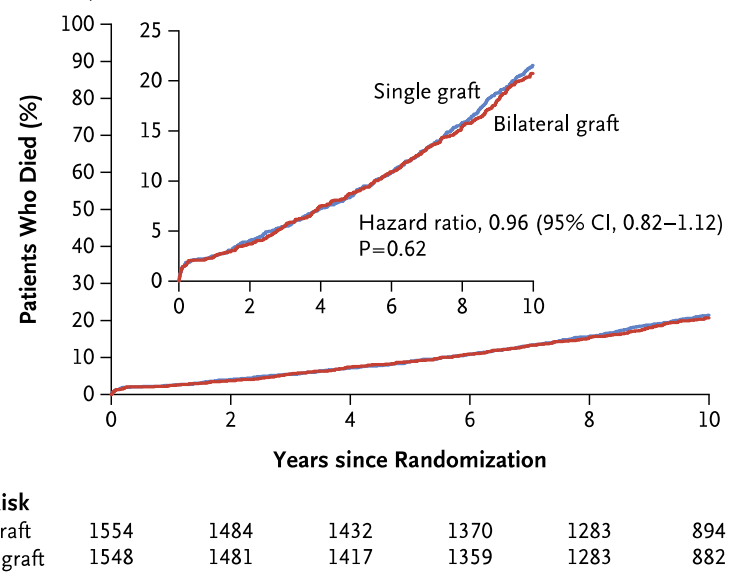

b Composite of Death from Any Cause, Myocardial Infarction, or Stroke at $10 \mathrm{Yr}$

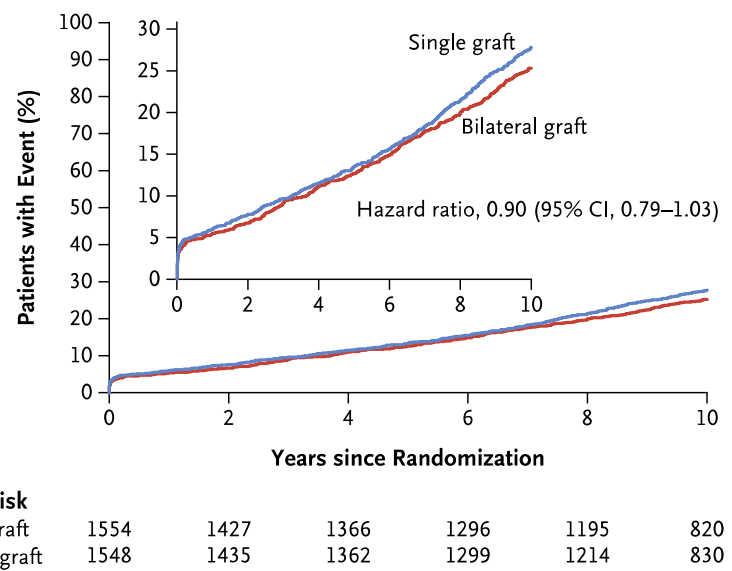

Fig. 1 Ten-year outcome of the ART trial Intention To Treat analysis for Death and Composite of Death from any cause, myocardial infarction or stroke (reproduced with permission NEJM 2019)

At the conception of ART trial in 2002, the potential benefit of the radial artery over saphenous vein graft on CABG outcomes had not been established. In a recent publication in the New England Journal of Medicine, the RADIAL Database investigators reported significantly better 5-year outcomes for the radial artery in comparison to saphenous vein, in terms of a reduced composite endpoint of mortality, MI and repeat revascularisation that was clearly attributable to the fact that the angiographic failure rate of the radial artery was $8 \%$ in comparison to $20 \%$ of vein grafts [6]. It can be speculated that with continuing attrition of vein grafts with longer-term follow-up, the gap between these surgical strategies may increase further.

A further possibility is that the high use of guidelinedirected medical therapy of antiplatelet medication, statins and beta-blockers may have slowed vein graft failure and therefore narrowed any potential differences between the groups.

However, another striking effect in the ART trial was the rate of crossover from BITA to SITA. Overall in the Trial, it was $14 \%$ but varied from 0 to $100 \%$ per individual surgeon-an effect that impacted adversely on 5-year outcomes [7]. Such high levels of cross-overs clearly indicate that some surgeons were not sufficiently skilled at BITA grafting. And the 10year survival data in the ITT analysis was clearly in favour of surgeons performing more than 50 operations, with significantly better survival. It is also noteworthy that in the hands of the highest volume surgeon in the ART trial, who recruited 416 patients with a cross-over of $1.2 \%$ from BITA to SITA, there was a clear survival benefit of BITA grafts in the intention to treat analysis.

The crucial importance of surgeon experience was also noted in the trials of on-pump and off-pump surgery. In the ROOBY Trial, where the entry criterion was to have previously performed 20 off-pump CABG operations, there were markedly inferior outcomes with off-pump surgery at 5 years [3]. In contrast, in the largest relevant trial to address this question, the CORONARY Trial $(n=4752)$, where the respective entry criterion was $>100$ off-pump operations, patient survival was identical at 5 years [4]. The findings of the ART and the ROOBY trials, where significant numbers of patients crossed-over or were operated by some surgeons who were clearly not as experienced as expected, have had a material influence on potential adverse outcomes in these trials. There is a clear message that in future trials there must be a quality assurance of surgeon ability to competently perform the intended operation.

In summary, different surgeons can take different messages from the ART Trial. For those who are against or do not believe in multiple arterial grafts, they will adopt and invoke the ITT analysis. In contrast, surgeons who advocate multiple arterial grafts, based on the overwhelming angiographic evidence of their superior patency compared to vein grafts, will continue to perform multiple arterial grafts citing the AT analysis of ART. A more definitive answer will not be available until the completion of the ROMA Trial [8] (a randomised trial of a single versus two arterial grafts where either the radial artery or a second ITA can be used according to surgeon preference and experience) expected in around 2025. Until then, the debate will continue. 
Fig. 2 Ten-year outcome of the ART trial As Treated Analysis for Death and Composite of Death from any cause, myocardial infarction or stroke (reproduced with permission NEJM 2019)

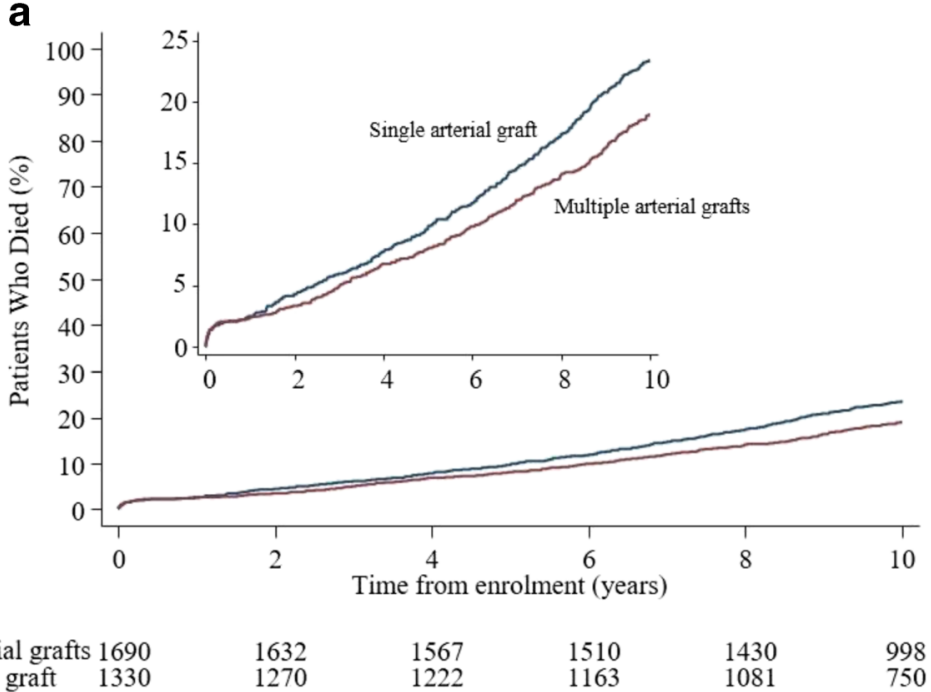

No. at Risk

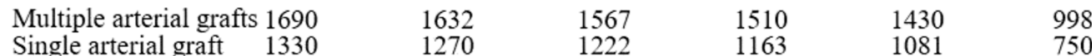

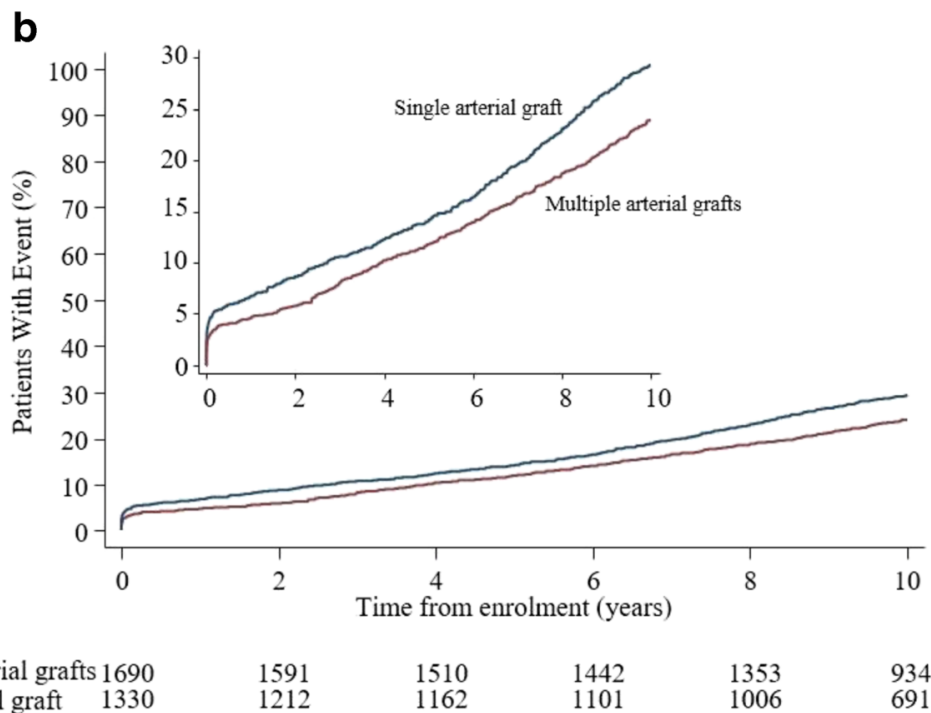

\section{References}

1. Favaloro RG. Saphenous vein autograft replacement of severe segmental coronary artery occlusion: operative technique. Ann Thorac Surg. 1968;5:334-9.

2. Taggart DP, D'Amico R, Altman DG. Effect of arterial revascularisation on survival: a systematic review of studies comparing bilateral and single internal mammary arteries. Lancet. 2001;358:870-5.

3. Shroyer AL, Hattler B, Wagner TH, et al. Five-year outcomes after on-pump and off-pump coronary-artery bypass. N Engl J Med. 2017;377:623-32.

4. Lamy A, Devereaux PJ, Prabhakaran D, et al. Five-year outcomes after off-pump or on-pump coronary-artery bypass grafting. N Engl J Med. 2016;375:2359-68.

5. Taggart DP, Benedetto U, Gerry S, et al. Bilateral versus single internal thoracic artery grafts at 10 years. N Engl J Med. 2019;380: 437-46.
6. Gaudino M, Benedetto U, Fremes S, et al. Radial-artery or saphenous-vein grafts in coronary-artery bypass surgery. $\mathrm{N}$ Engl $\mathrm{J}$ Med. 2018;378:2069-77.

7. Benedetto U, Altman DG, Flather M, et al. Incidence and clinical implications of intraoperative bilateral internal thoracic artery graft conversion: insights from the arterial revascularization trial. J Thorac Cardiovasc Surg. 2018;155:2346-55.

8. Gaudino M, Alexander JH, Bakaeen FG, et al. Randomized comparison of the clinical outcome of single versus multiple arterial grafts: the ROMA trial-rationale and study protocol. Eur J Cardiothorac Surg. 2017;52:1031-40.

Publisher's note Springer Nature remains neutral with regard to jurisdictional claims in published maps and institutional affiliations. 